\title{
Giant thymolipoma in association with a high production of carbohydrate antigen 19-9 and an increased acetylcholine antibody titer
}

Valerio Perna, MD, Ricardo Morera, MD, Ricard Ramos, MD, Ivan Macia, MD, and Juan Moya, MD, Barcelona, Spain

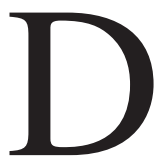

uring preoperative examination for chronic sinusitis, a 26-year-old man displayed an abnormal mass shadow on chest radiography. The patient was referred to us for further evaluation.

Chest radiography revealed a large mass in the mid-lower mediastinum that silhouetted bilateral heart borders and conformed to the shape of the heart, simulating cardiomegaly (Figure 1).

Physical examination revealed no abnormalities. Laboratory data were within the normal range, except for an incidental finding of increased serum carbohydrate antigen 19-9 (CA 19-9) level at $150.67 \mathrm{U} / \mathrm{mL}$ (normal, $<40 \mathrm{U} / \mathrm{mL}$ ) and an increased acetylcholine antibody titer. Computed tomography (CT) of the chest revealed a large inhomogeneous anterior mediastinal mass composed of fatty areas that surrounded the heart entirely and extended into both hemithoraces (Figure 2). CT-guided fine-needle aspiration biopsy revealed thymolipoma.

The tumor was approached through a double thoracotomy. The mass was spread expansively anterior to the pericardium, wrapping the left phrenic nerve and extending inferiorly into both hemithoraces. The tumor was well encapsulated, measuring $17 \times 13 \times 5 \mathrm{~cm}$ and weighing $700 \mathrm{~g}$ at the right lobe and measuring $21 \times 17 \times 15 \mathrm{~cm}$ and weighing $1000 \mathrm{~g}$ at the left lobe. The postoperative course was uneventful, and serum CA 19-9 levels normalized within 6 weeks. After 6 months, the patient maintained normal serum CA 19-9 levels, and changes of the acetylcholine antibody titer were not observed.

\section{Discussion}

Thymolipoma is a rare, benign, and slow-growing tumor accounting for $2 \%$ to $9 \%$ of all thymic neoplasms. The tumor occurs most frequently in young adults, with no sex predilection. Most patients with thymolipoma are asymptomatic and display large anterior mediastinal masses on chest radiography when the tumor grows on the left side of the chest. A histopathologic evaluation, such as fine-needle biopsy, is needed

From the Thoracic Surgery Department, Hospital Universitario de Bellvitge, Barcelona, Spain.

Received for publication Dec 27, 2005; accepted for publication Jan 24, 2006.

Address for reprints: Valerio Perna, Ronda-del General Mitre 65 4-1, Barcelona 08017, Spain (E-mail: 37987vp@comb.es).

J Thorac Cardiovasc Surg 2006;131:1412-3

$0022-5223 / \$ 32.00$

Copyright $\odot 2006$ by The American Association for Thoracic Surgery doi:10.1016/j.jtcvs.2006.01.030

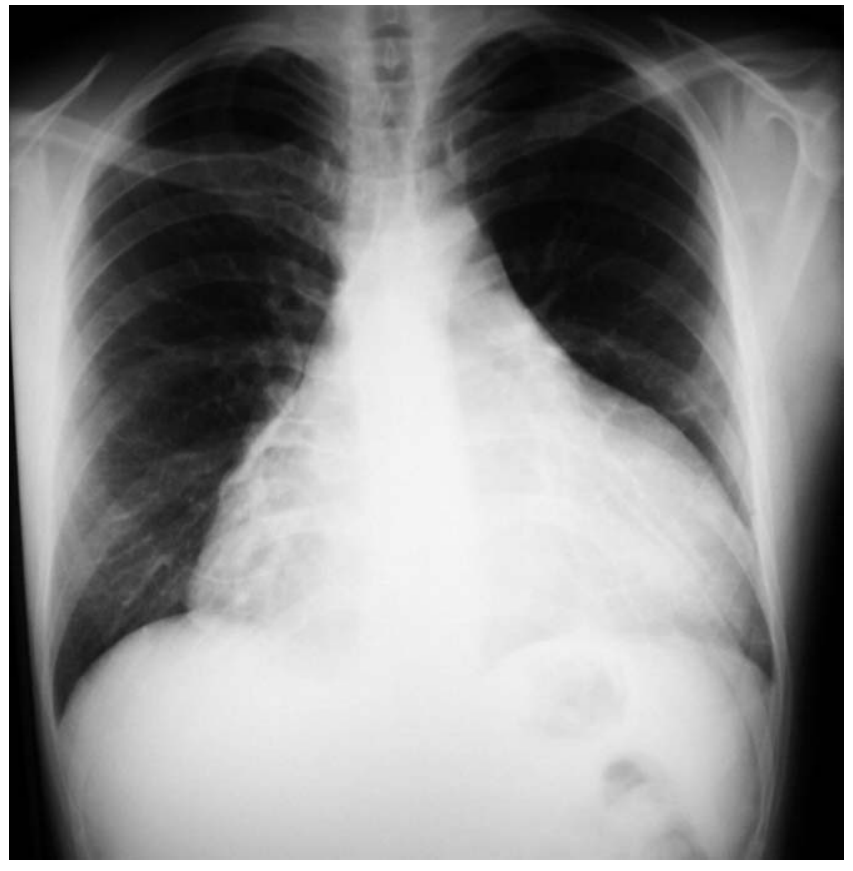

Figure 1. Chest radiography showing a large mediastinal mass extending into both the right and left hemithoraces.

to differentiate thymolipoma from lipoma, thymic hyperplasia, and liposarcoma; CT and magnetic resonance imaging can narrow the differential diagnoses.

Although several theories have been proposed, the pathogenesis of thymolipoma remains controversial. One theory, citing the haphazard mixture of thymic parenchyma and fat, holds that it is a thymic hamartoma. ${ }^{1}$ A malformative theory ${ }^{2}$ is supported by a reported case in which parathyroid tissue was admixed with a tumor resembling thymolipoma. This case suggests a possible origin from aberrant development of the third pharyngeal pouch. Other theories suggest that thymolipoma represents fatty regression of a thymoma or of a previously hyperplastic thymus. Perhaps the most intriguing theory is of thymolipoma representing a benign tumor of specialized thymic stroma ${ }^{3}$ that maintains its relationship with the thymic epithelium as it grows. In this scenario thymolipoma would be analogous to other tumors of specialized stroma, such as fibroadenoma of the breast and adenofibroma of the uterus. Cases of malignant tumor of specialized thymic stroma, thymoliposarcoma, have been reported ${ }^{4}$ to further support this analogy. 


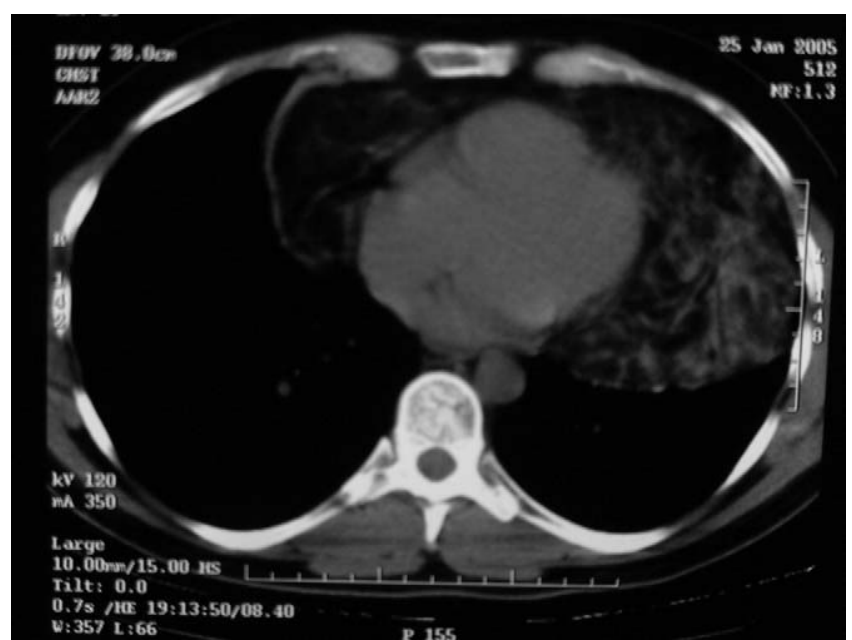

Figure 2. Spiral computed tomographic scan identified a massive heterogeneous mass with fat attenuation, with soft tissue extending widely into the bilateral inferior hemithoraces.
According to our review of the literature, there has been described only a single case of thymolipoma that seemed to produce CA $19-9,{ }^{5}$ a protein originally identified on the surface of colon cancer cells by using murine monoclonal antibodies. Interestingly, the thymolipoma in our case is associated with an increased acetylcholine antibody titer without clinical evidence of myasthenia gravis. Studies of larger case series are necessary to elucidate the relationships between a high production of CA 19-9 and an increased acetylcholine antibody titer in patients with thymolipoma.

\section{References}

1. Moran CA, Rosado-de-Christenson M, Suster S. Thymolipoma: clinicopathologic review of 33 cases. Mod Pathol. 1995;8:741-4.

2. van Hoeven KH, Brennan MF. Lipothymoadenoma of the parathyroid. Arch Pathol Lab Med. 1993;117:312-4.

3. Hall GFM. A case of thymolipoma with observations on a possible relationship to intrathoracic lipomata. Br J Surg. 1948;36:321-4.

4. Havlicek F, Rosai J. A sarcoma of thymic stroma with features of liposarcoma. Am J Clin Pathol. 1984;82:217-24.

5. Shinichi M, Kan O, Masafumi H, Masakatsu H, Takayuki S. Thymolipoma with high production of carbohydrate antigen 19-9. J Thorac Cardiovasc Surg. 2004;127:1845-7.

\section{Single-stage repair of a large acquired tracheoesophageal fistula with interposition of 2 muscle pedicle flaps and laparoscopic gastrojejunostomy}

Vishwanath Golash, MS, FRCS, Salalah, Sultanate of Oman

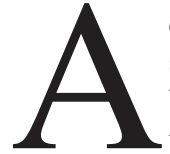

cquired tracheoesophageal fistula (TEF) is a rare but serious complication of prolonged endotracheal intubation. The main causative factor probably is the pressure of the overinflated cuff, leading to ischemia and tissue necrosis. The presence of a nasogastric tube adds further to the compression against the endotracheal cuff, resulting in TEF. I present the successful repair of a large TEF as a single-stage procedure.

From the Department of Surgery, Sultan Qaboos Hospital, Salalah, Sultanate of Oman.

Received for publication Nov 11, 2005; revisions received Dec 11, 2005; accepted for publication Dec 16, 2005.

Address for reprints: Vishwanath Golash, MS, FRCS, Department of Surgery, Sultan Qaboos Hospital, PO Box 98, Salalah, Pin Code 211, Sultanate of Oman (E-mail: golash@omantel.net.om and haritagolash@hotmail.com).

J Thorac Cardiovasc Surg 2006;131:1413-4

$0022-5223 / \$ 32.00$

Copyright $\odot 2006$ by The American Association for Thoracic Surgery doi:10.1016/j.jtcvs.2005.12.069

\section{Clinical Summary}

A 35-year-old full-term woman was referred from a remote area with a history of obstructed labor for the previous 3 days. On examination,

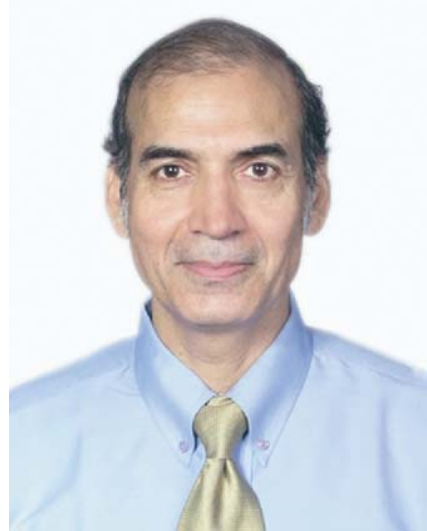

Dr Golash she was ill looking, pale, and toxic; had a blood pressure (BP) of 170/110 mm Hg; had a pulse of 104 beats/min; was febrile; and had gross peripheral edema. Per the abdomen, there were no palpable uterine contractions and no audible fetal heart sounds. On vaginal examination, the cervix was fully dilated. Urgent ultrasonography of the abdomen showed full-term uterus and no fetal movement. Gross crepitations were heard on both sides of the chest. Her initial diagnosis was pregnancy-induced hypertension, preeclampsia, intrauterine death of the child, and septicemia. Her investigations showed anemia, hypoalbuminemia, respiratory and metabolic acidosis, hypoxia, and septicemia. The chest radiograph and computed tomographic (CT) scan were suggestive of aspiration pneumonia. She was resuscitated. The dead fetus and placenta were delivered by means of emergency caesarian section. Postoperatively, she was ventilated because of poor oxygen saturation. Her subsequent repeated chest 